\title{
Search for Anti-EA(D) Antibodies in Subjects with an "Isolated VCA IgG" Pattern
}

\author{
Massimo De Paschale, Debora Cagnin, Teresa Cerulli, Maria Teresa Manco, Carlo Agrappi, \\ Paola Mirri, Arianna Gatti, Cristina Rescaldani, and Pierangelo Clerici
}

Microbiology Unit, Hospital of Legnano, Via Candiani 2, 20025 Legnano MI, Italy

Correspondence should be addressed to Massimo De Paschale, massimo.depaschale@ao-legnano.it

Received 5 January 2010; Accepted 16 May 2010

Academic Editor: Vasco Azevedo

Copyright (C) 2010 Massimo De Paschale et al. This is an open access article distributed under the Creative Commons Attribution License, which permits unrestricted use, distribution, and reproduction in any medium, provided the original work is properly cited.

\begin{abstract}
The presence of an "isolated viral capsid antigen (VCA) IgG" pattern in serum is not easy to interpret without the aid of further tests, such as specific immunoblotting or a virus genome search, that often give rise to organisational and economic problems. However, one alternative is to use an enzyme-linked immunosorbent assay (ELISA) to detect anti-early antigen (EA) antibodies, which can be found in about $85 \%$ of subjects with acute Epstein-Barr virus (EBV) infections. The purpose of this work was to search for anti-EA(D) antibodies in 130 samples with an isolated VCA IgG pattern at ELISA screening and classified as being indicative of past (102 cases) or acute (28 cases) infection on the basis of the immunoblotting results. Thirty-seven samples (28.5\%) were positive for anti-EA(D), of which $25(89.3 \%)$ had been classified by immunoblotting as indicating acute and $12(11.8 \%)$ past EBV infection. This difference was statistically significant $(P<.01)$. The results of our search for anti-EA(D) antibodies correctly identified nearly $90 \%$ of acute (presence) or past EBV infections (absence). When other tests are not available, the search for anti-EA antibodies may therefore be helpful in diagnosing patients with an isolated VCA IgG pattern at screening tests.
\end{abstract}

\section{Introduction}

The most common manifestation of primary Epstein-Barr virus (EBV) infection is acute infectious mononucleosis, a self-limited clinical syndrome that most frequently affects adolescents and young adults. Serology is one of the cardinal means of diagnosing EBV infection as antibody search for viral capsid antigen (VCA), nuclear antigen (EBNA), and early antigen (EA) makes it possible to define the status of the infection $[1,2]$. The three parameters of VCA IgG, VCA IgM, and EBNA-1 IgG generally make it simple to distinguish acute and past infection in immunocompetent patients [3]. The presence of VCA IgG and VCA IgM in the absence of EBNA-1 IgG is indicative of acute infection, whereas the presence of VCA IgG and EBNA-1 IgG in the absence of VCA IgM is typical of past infection.

However, the presence of an isolated VCA IgG pattern may appear in about $8 \%$ of all subjects with at least one EBV infection marker [4] and may be difficult to interpret because it can be found in patients with prior infection as well as in those with acute infection. In fact, in some cases, VCA IgM may appear 1-2 weeks after VCA IgG, or for a very short time, or at such a low concentration as to be missed by conventional laboratory tests [5]; furthermore, VCA IgM may persist for a long time after acute infection and still be detected after 80 weeks together with EBNA-1 IgG. The picture is made even more complicated by the fact that $5 \%$ of patients produce no EBNA IgG after EBV infection $[5,6]$ and, even when it is actually produced, it may be lost over time especially in the case of immunosuppression $[5,7,8]$. In such cases, in addition to following up the patient in order to evaluate possible variations in antibody titres, it is useful to perform further laboratory tests such as immunoblotting for various specific IgG antibodies, a VCA IgG avidity test, or searches for heterophile antibodies or viral genome using molecular biology techniques [9]. Tests such as a viral genome search or immunoblotting are particularly useful for defining the status of infection [10-12]. In particular, immunoblotting [13] using recombinant antigens such as p72 (EBNA-1), p18 (VCA), p23 (VCA), p54 (EA), p138 
TABLE 1: Antibody specificity at EBV immunoblotting in 103 samples with an isolated VCA IgG pattern at ELISA screening.

\begin{tabular}{|c|c|c|c|c|c|c|c|}
\hline \multirow{2}{*}{ No. } & \multicolumn{7}{|c|}{ Anti-EBV immunoblotting } \\
\hline & gp $250 / 350$ & p54 & p72 & p138 & $\mathrm{p} 23$ & $\mathrm{p} 18$ & Infection \\
\hline 102 & $27(26.5 \%)$ & $16(15.7 \%)$ & $65(63.7 \%)$ & $30(29.4 \%)$ & $99(97.1 \%)$ & $102(100 \%)$ & Past \\
\hline 28 & $6(21.4 \%)$ & $27(96.4 \%)$ & $0(0 \%)$ & $26(92.9)$ & $21(75.0 \%)$ & $0(0 \%)$ & Acute \\
\hline
\end{tabular}

TABLE 2: Results of search for anti-EA(D) antibodies in relation to results of anti-EBV immunoblotting.

\begin{tabular}{lccc}
\hline \multirow{2}{*}{ Anti-EBV immunoblotting } & \multicolumn{2}{c}{ Anti-EA(D) antibodies } \\
& Negative & Positive & Total \\
\hline Anti-p18 negative (acute infection) & $3(10.7 \%)$ & $25(89.3 \%)$ & 28 \\
Anti-p18 positive (past infection) & $90(88.2 \%)$ & $12(11.8 \%)$ & 102 \\
\hline
\end{tabular}

(EA), and gp350/250 (MA = membrane antigen $)$ can detect anti-VCA p18 antibodies which, as they are produced late during the course of EBV infection, are considered substitutes for EBNA-1 IgG [7]. Unfortunately, economic and organisational problems still limit the widespread use of this and molecular biology techniques.

One possible alternative is to look for an additional serological marker that can be easily detected by means of ELISA cases, such as anti-early antigen (EA) antibodies. These consist of a diffuse (D) and restricted component (R) that reflect the two different patterns originally observed using immunofluorescence. About $70 \%-85 \%$ of patients with acute EBV infection are anti-EA(D) antibody positive for up to three months after symptom onset [7, 14]. However, high titres of these antibodies are present during EBV reactivation [15] and in patients with nasopharyngeal carcinoma [16], and they can also be found in 20\%-30\% of healthy subjects with a history of EBV infection $[17,18]$. Consequently, a search for anti-EA(D) antibodies alone does not make it possible to identify any stage of the disease [9], but its combination with other parameters may be useful for making a laboratory diagnosis of acute EBV infection [19]. A recent study showed a pattern of VCA IgG positive and VCA IgM, EBNA-1 IgG, and anti-EA(D) IgG negative (and heterophile antibody negative) as associated with past infection, while a pattern of VCA IgG and anti-EA(D) IgG positive but VCA IgM and EBNA-1 IgG negative has a still unclear meaning [20].

The aim of this study was to evaluate the usefulness of an ELISA for anti-EA(D) antibodies in subjects with isolated VCA IgG (VCA IgG positive and VCA IgM and EBNA-1 IgG negative) at ELISA screening, typed as being indicative of a past or acute infection on the basis of immunoblotting.

\section{Material and Methods}

One hundred and thirty serum samples were selected with an isolated VCA IgG pattern (VCA IgM and EBNA-1 IgG negative, but VCA IgG positive) at ELISA screening. The samples came from 69 females and 61 males (mean age 32.9 years, range 3-88) with suspected EBV infection and were sent by general practitioners to the Microbiology Unit of Legnano Hospital to be searched for specific antibodies.

In our Unit, ELISA routine screening includes the simultaneous search of VCA IgG, VCA IgM, and EBNA-1 IgG (ETI-VCA-G, ETI-EBV-M reverse, ETI-EBNA-G, DiaSorin, Saluggia, Italy) and in case of isolated VCA IgG, an EBV immunoblotting (RecomBlot EBV IgG, Mikrogen, Neuried, Germany) is performed.

On the basis of the presence or absence of anti-p18 at immunoblotting, all samples were divided into 102 cases with past and 28 with acute infection (Table 1). They were also tested for the presence of heterophile antibodies (MonoSlide, Diesse, Siena, Italy) and anti-EA(D) antibodies, using an ELISA (ETI-EA-G, DiaSorin, Saluggia, Italy). Recombinant polypeptide antigen $(47 \mathrm{kDa})$ used in ELISA is correlated to the recombinant p54 antigen of immunoblotting. The data were statistically analysed using Fisher's exact test and the $\chi^{2}$ test.

\section{Results}

Thirty-seven samples (28.5\%) were positive and 93 (71.5\%) negative for anti-EA(D). Among the cases classified by immunoblotting as indicating acute or past EBV infection, 25 $(89.3 \%)$ and $12(11.8 \%)$ were respectively positive for anti$\mathrm{EA}(\mathrm{D})$ (Table 2). This difference was statistically significant $(P<.01)$.

Among the 28 cases with acute infection at immunoblotting, $16(57.1 \%)$ had heterophile antibodies and, of these, 15 (93.8\%) were positive for anti-EA(D) antibodies.

Table 3 shows the correlation between anti-EA(D) positivity and individual antibody specificity at immunoblotting. The differences were statistically significant in the case of $\mathrm{p} 54$, p72, p138, and p18 $(P<.01)$.

\section{Discussion}

The presence of an isolated VCA IgG serological pattern is not easy to interpret because it can be found in patients with prior EBV infection who have lost or never shown EBNA$1 \mathrm{IgG}$ as well as in those with acute infection in whom VCA IgM appears late or disappears early. However, it is important to be able to interpret this pattern correctly when a laboratory needs to quickly respond to questions of the clinicians. Without having to wait for a second sample in the hope of a change in the antibody pattern, it would seem to be useful to use a further marker in addition to the three routine tests (VCA-IgG, IgM and EBNA-1 IgG). Given that immunoblotting or a search for virus genome can create organisational and economic problems, an easily automated 
TABLE 3: Correlations between the presence of anti-EA(D) antibodies and antibody specificity at EBV immunoblotting.

\begin{tabular}{lccccccc}
\hline $\begin{array}{l}\text { Anti-EA(D) } \\
\text { antibodies }\end{array}$ & No. & gp250/350 & p54 & p72 & p138 & p23 & p18 \\
\hline Positive & 37 & $11(29.7 \%)$ & $34(91.9 \%)$ & $7(18.9 \%)$ & $32(86.5 \%)$ & $32(86.5 \%)$ & $12(32.4 \%)$ \\
Negative & 93 & $22(23.7 \%)$ & $13(14.0 \%)$ & $58(62.4 \%)$ & $24(25.8 \%)$ & $89(95.7 \%)$ & $92(98.9 \%)$ \\
$P$ & & NS & $<.01$ & $<.01$ & $<.01$ & NS & $<.01$ \\
\hline
\end{tabular}

NS: not significant.

test such as an ELISA, whose costs are comparable with those of other screening tests, could be a viable alternative.

Anti-EA(D) antibodies could make a useful marker because they are normally present during the acute phase, even though they are not always produced and sometimes remain for a long time after the primary infection (their presence has been reported in $20 \%-30 \%$ of patients with past infections) $[17,18]$. We found them in about $12 \%$ of our patients with an isolated VCA IgG pattern and a past infection identified by means of immunoblotting, but in $90 \%$ of those with an acute infection. Compared to more recent studies in literature [20], if our study is concordant in indicating, in this group of patients, the absence of antiEA(D) IgG as mark of past infection, on the other hand the presence of anti-EA(D) IgG correlates with an acute infection.

In conclusion, the results of our search for anti-EA(D) antibodies correctly identified nearly $90 \%$ of acute (presence of anti-EA(D)) or past EBV infections (absence of anti$\mathrm{EA}(\mathrm{D})$ ), which indicate that, in laboratory routine, it can be helpful in diagnosing immunocompetent patients with an isolated VCA IgG pattern when other more sophisticated tests are not available.

\section{References}

[1] K. F. Macsween and D. H. Crawford, "Epstein-Barr virusrecent advances," Lancet Infectious Diseases, vol. 3, no. 3, pp. 131-140, 2003.

[2] A. Svahn, M. Magnusson, L. Jägdahl, L. Schloss, G. Kahlmeter, and A. Linde, "Evaluation of three commercial enzyme-linked immunosorbent assays and two latex agglutination assays for diagnosis of primary Epstein-Barr virus infection," Journal of Clinical Microbiology, vol. 35, no. 11, pp. 2728-2732, 1997.

[3] B. C. Gärtner, R. D. Hess, D. Bandt, A. Kruse, A. Rethwilm, K. Roemer, and N. Mueller-Lantzsch, "Evaluation of four commercially available Epstein-Barr virus enzyme immunoassays with an immunofluorescence assay as the reference method," Clinical and Diagnostic Laboratory Immunology, vol. 10, no. 1, pp. 78-82, 2003.

[4] M. de Paschale, C. Agrappi, M. T. Manco, P. Mirri, E. F. Viganò, and P. Clerici, "Seroepidemiology of EBV and interpretation of the "isolated VCA IgG" pattern," Journal of Medical Virology, vol. 81, no. 2, pp. 325-331, 2009.

[5] G. Bauer, "The rational basis for efficient Epstein-Barr virus (EBV) serology," Clinical Laboratory, vol. 41, no. 9, pp. 623634, 1995.

[6] M. Kampmann, K. Henninger, and G. Bauer, "Determination of antibodies directed specifically against Epstein-Barr virus nuclear antigen-1 (EBNA-1) by anticomplementary immunofluorescence (ACIF)," Medical Microbiology Letters, vol. 2, pp. 1-8, 1993.

[7] G. Bauer, "Simplicity through complexity: immunoblot with recombinant antigens as the new gold standard in EpsteinBarr virus serology," Clinical Laboratory, vol. 47, no. 5-6, pp. 223-230, 2001.

[8] V. Vetter, L. Kreutzer, and G. Bauer, "Differentiation of primary from secondary anti-EBNA-1-negative cases by determination of avidity of VCA-IgG," Clinical and Diagnostic Virology, vol. 2, no. 1, pp. 29-39, 1994.

[9] R. D. Hess, "Routine Epstein-Barr virus diagnostics from the laboratory perspective: still challenging after 35 years," Journal of Clinical Microbiology, vol. 42, no. 8, pp. 3381-3387, 2004.

[10] K. H. Chan, M. H. Ng, W. H. Seto, and J. S. M. Peiris, "EpsteinBarr Virus (EBV) DNA in sera of patients with primary EBV infection," Journal of Clinical Microbiology, vol. 39, no. 11, pp. 4152-4154, 2001.

[11] R. Luderer, M. Kok, H. G. M. Niesters, R. Schuurman, O. de Weerdt, and S. F. T. Thijsen, "Real-time Epstein-Barr virus PCR for the diagnosis of primary EBV infections and EBV reactivation," Molecular Diagnosis, vol. 9, no. 4, pp. 195-200, 2005.

[12] R. D. Holmes and R. J. Sokol, "Epstein-Barr virus and posttransplant lymphoproliferative disease," Pediatric Transplantation, vol. 6, no. 6, pp. 456-464, 2002.

[13] J. Schubert, W. Zens, and B. Weissbrich, "Comparative evaluation of the use of immunoblots and of IgG avidity assays as confirmatory tests for the diagnosis of acute EBV infections," Journal of Clinical Virology, vol. 11, no. 3, pp. 161172, 1998.

[14] E. T. Lennette and W. Henle, "Epstein-Barr virus infections: clinical and serologic feature," Laboratory Management, vol. 25, pp. 23-26, 1987.

[15] W. Henle and G. Henle, "Epstein-Barr virus-specific serology in immunologically compromised individuals," Cancer Research, vol. 41, no. 11, pp. 4222-4225, 1981.

[16] P. V. Coyle, D. Wyatt, J. H. Connolly, and G. A. Lynch, "Antibodies to Epstein-Barr virus in patients with nasopharyngeal carcinoma in Northern Ireland," Irish Journal of Medical Science, vol. 156, no. 6, pp. 182-184, 1987.

[17] E. T. Lennette, "Epstein-Barr virus (EBV)," in Diagnostic Procedures for Viral, Rickettsial, and Chlamydial Infections, E. H. Lennette, D. A. Lennette, and E. T. Lennette, Eds., pp. 299312, American Public Health Association, Washington, DC, USA, 1995.

[18] P. Wohlrabe, I. Farber, P. Wutzler, and R. Uhlig, "Antibodies to Epstein-Barr virus-induced early antigens in blood donors," Acta Virologica, vol. 33, no. 4, pp. 344-348, 1989.

[19] D. W. T. Ho, P. R. Field, and A. L. Cunningham, "Rapid diagnosis of acute Epstein-Barr virus infection by an indirect enzyme-linked immunosorbent assay for specific 
immunoglobulin M (IgM) antibody without rheumatoid factor and specific IgG interference," Journal of Clinical Microbiology, vol. 27, no. 5, pp. 952-958, 1989.

[20] J. S. Klutts, B. A. Ford, N. R. Perez, and A. M. Gronowski, "Evidence-based approach for interpretation of Epstein-Barr virus serological patterns," Journal of Clinical Microbiology, vol. 47, no. 10, pp. 3204-3210, 2009. 

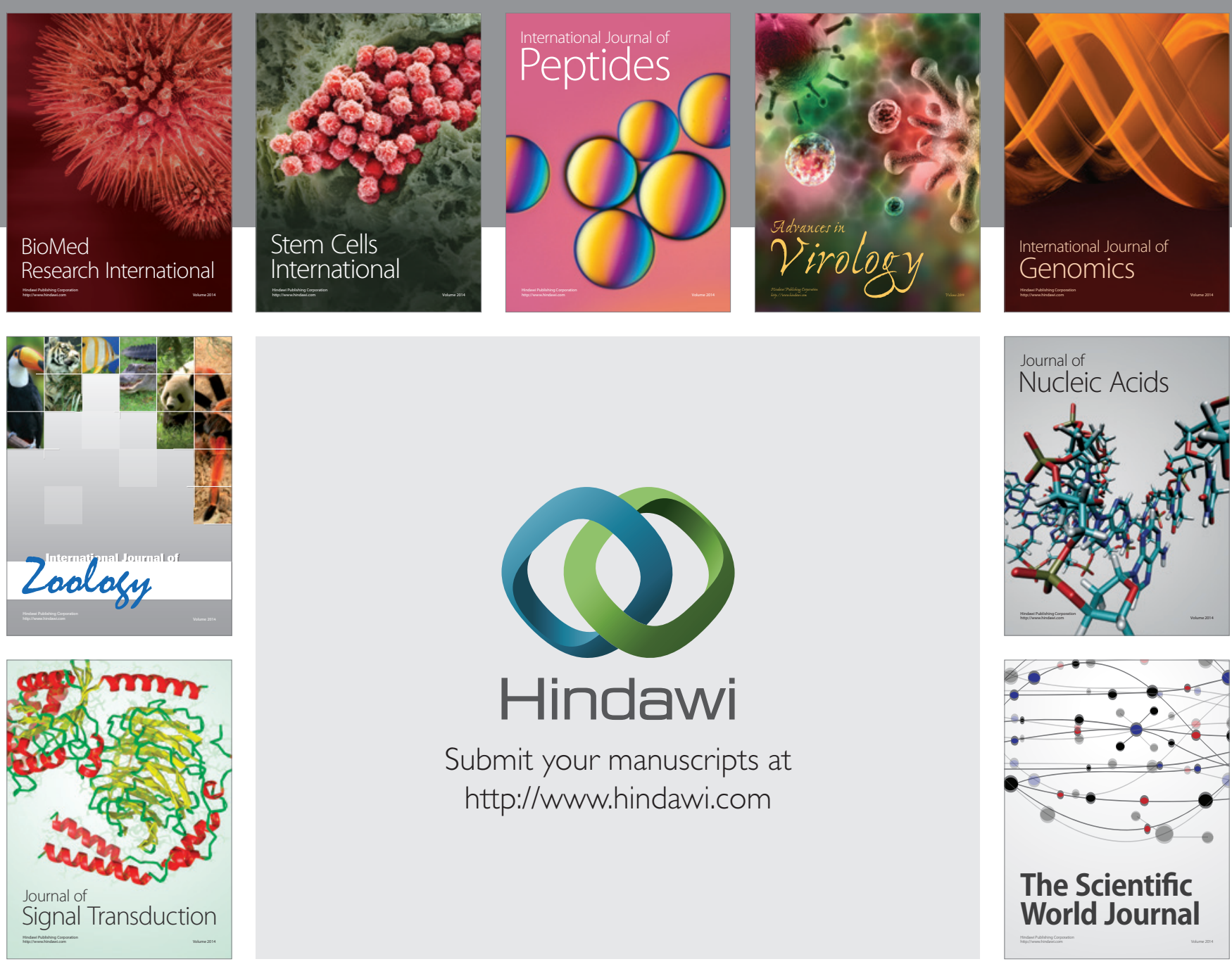

Submit your manuscripts at

http://www.hindawi.com
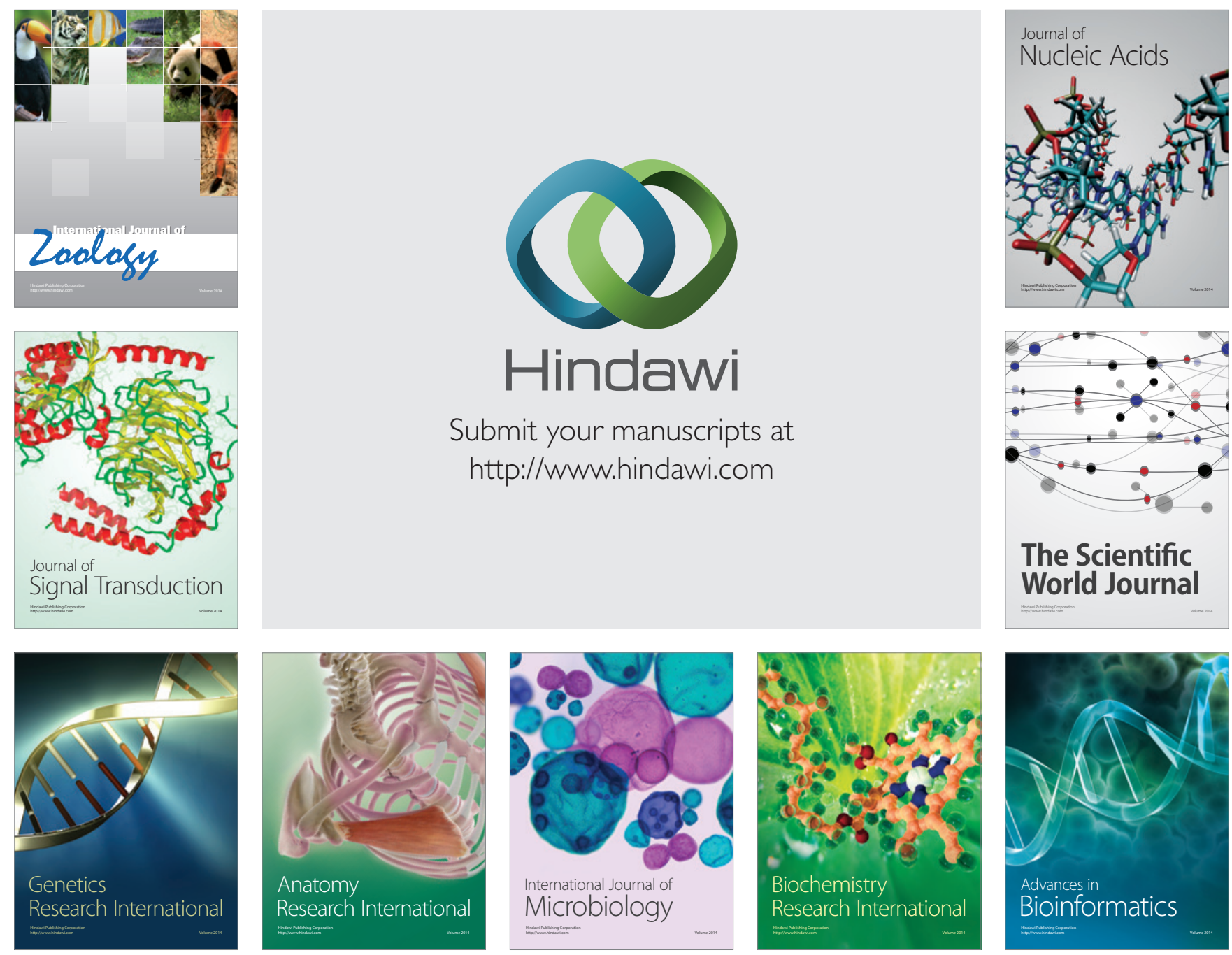

The Scientific World Journal
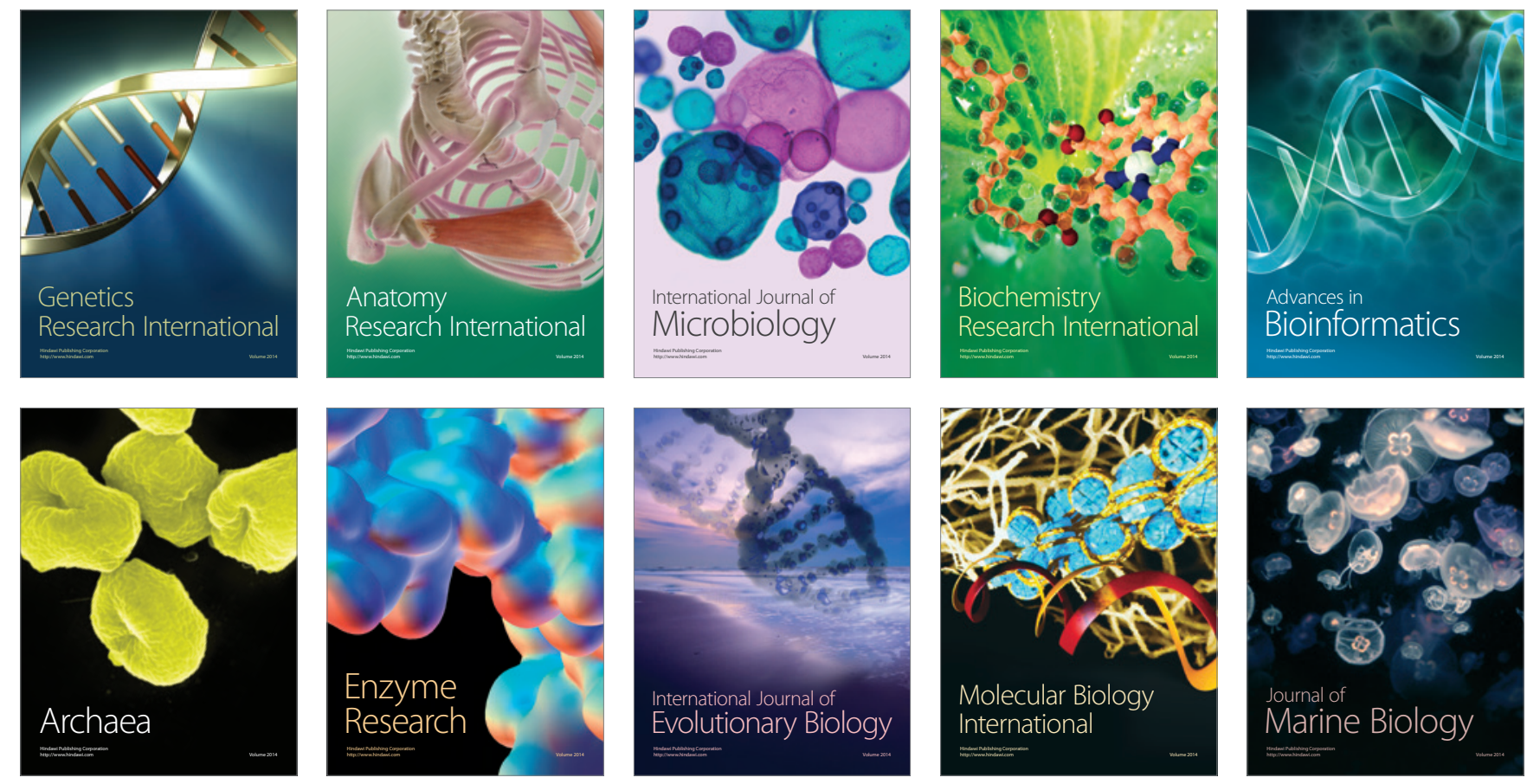